\title{
Universities More than Knowledge: Foster the Quality in Research Processes
}

\author{
Jaddy Brigitte Nielsen Niño
}

\begin{abstract}
Research is not a new discussion topic for the Colombian academic community. Therefore, institutions of higher education such as Universidad La Gran Colombia attempt to generate alternatives to foster research processes in undergraduate students. Unknown, this is a difficult task for researchers because they are usually reluctant to search, track and appropriate knowledge supported with solid theoretical basis that allow them to generate an academic discourse beyond the collective imagination. In fact, this research was focused on creating academic writings from comparative researches that were enhanced and contextualized within the international seminar held at the Missouri State University in the United States of America. The analysis of data shows that the research process is always a joint task as there is an academic discipline from the student and constant feedback from the professor or researcher.
\end{abstract}

Index Terms-Academic writing, international seminar, research process, undergraduate students, Universidad La Gran Colombia.

\section{INTRODUCTION}

Researching and writing some findings in a different language, specially English is not an easy task for undergraduate students in Latin-American and many of them prefer to avoid it. This article focuses on research about the quality of research writing processes that includes some Colombian students who attend an international seminar at Missouri State University in the United States of America. There are international statements where research is an excellent option for society. On the other hand, in Latin America, the situation is completely different, and for that reason, some universities are starting to re-think their research practices and include their professors and different resources to improve the research process such as internationalization curricula.

The researcher implements some steps to foster the quality of research writing in their students, but it is not easy because the researcher should find some strategies to motivate the students and give feedback any time when research and writing processes are involved according to their real contexts.

The research takes into account different environments and members' perspective; some of them are about bilingual education, assessment and the teacher role in Colombia and around the world. Therefore, some Grancolombian students

Manuscript received June 8, 2015; revised January 15, 2016. This work was supported in part by the Universidad La Gran Colombia in Bogotá

Jaddy Brigitte Nielsen Niño is with the Universidad La Gran Colombia, Bogotá CO. Research Department, School of Education, Colombia (e-mail: jaddy.nielsen@ugc.edu.co, brigittebrigitte9@gmail.com) are focus on international problems that include the language as a mediator especially in fields about inclusion, socio-cultural environment, teaching practice and pluricultural education based on empiric research. In fact, those topics are in a book and they are developed according students' discipline and experience supporting with the state of the problem.

\section{LITERATURE REVIEW}

Nowadays, educational processes including internationalization play an important role. Therefore, since 2013 some universities in Colombia had decided to carry out a curricular review of their degree programs. This article document relates only B.A. in English, which has developed according the organizational dynamics of academic teams, students and teachers' experiences about the program. This dynamic has also emerged workshops and regular meetings where staff have discussed how to improve the syllabus according to strengthen interdisciplinary integration and their academic departments that are part of the faculty (research and outreach and accreditation). Those meetings have laid the foundations for progress towards internationalization and the first steps to build a research culture without leaving aside the promotion of socio- critical thinking that characterizes many universities in Colombia.

In fact, staff continues working on the permanent updating of the curriculum of the Bachelor of English that is part of the Colombian Education University, gradually creating a solid base on the theoretical approaches and methodological aspects according to the specific needs and realities of the university context.

It is important to determine that culture, curriculum and education should not be seen and worked isolated from one to the other because they have an intrinsic correlation since humans noticed that the need to communicate (linguistic aspects), to organize (social aspects) and rules were created and chosen to seek protection and confidence (Leviathan-State). Therefore, education becomes a state's task, when the government needed to train individuals according to their interests and the school should be a place that include the "nationalization" [1]. For that reason, the government has developed and established educational policies and within the construction of a curriculum [2].

A book that is called "research and curriculum development" includes different points of view and perspectives about the curriculum but the authors have concluded that curriculum is an important process in teaching and learning [3] because a professor can define his/her aim with sufficient clarity if the student is able to illustrate or 
describe the kind of behavior expected in the society, when such behavior is observed can be recognized for the professor. This statement defines a target behavior, even some authors makes a distinction between objective and purpose, recognizing that the process of the systematic curriculum development based on the analysis of general statements and purposes, this helps to get more specific behavioral goals. In all, the relation of students' behaviors and academic principles can help to development the curriculum in a properly way.

Besides, those concepts have a close relationship according to the assertion of recently authors who talk about the importance of culture inside the curriculum [4] because men, women both educated and illiterate, and they have never doubted that ideas could guide behavior. In addition, everything in our experience leads us to the same conclusion: the activities are under the control of our values, contents and intentions. We can say that the claim that it is ideas that guide behavior, and not vice versa. Considered from a cultural materialist perspective, which is one of the biggest mistakes of modern anthropological, culture is socially learned as a way of life in human societies and covering all aspects of social life, including thinking and behavior and assert that in an institutional context is intended to form the individual according to the ethos. In this way, defined by sociology as the starting point of the ideas that shape the character of particular system or school of thought, which involves molding his character or way of being and will continue throughout their existence.

\section{FINDINGS}

First of all, for this analysis, the Grounded Theory approach was chosen because the data analysis procedure selected was offered. Grounded Theory [5] includes a procedure called "coding". In other words, the procedures listed or coding and analyzing the samples collected through the technique applied. There are four categories that emerged modeling writing, the role of feedback, theory for academic proposes and handling language rules.

\section{A. Category 1: Modeling Writing}

This category analyzes how to select a topic according to the context. In this case, Juan Meraz, the vice-president of Division for Diversity \& Inclusion at Missouri State University, talked with the students about inclusion and multicultural perspectives in his university. Taking into account that this issue is part of the main project, writing should start to know the person's context, but at the same time show an academic article. For instance, a sample written by the researcher, the vice-president and one students of the B.A program. It demonstrates motivation to the students tended to start their writing process, in the sense of content and well organization.

The structure written plan was given through an academic rubric. This helps them what to do and how to do it before writing. Definitely, academic staff will not forget that writing is one of the most important skills that foreign language students need to develop and it requires at the same time extensive, clear and specialized instruction [6]. Furthermore, students should know some techniques and activities the researcher decided to use for writing process, the abovementioned approach to writing, it is important for the researcher to be acquainted to the student's writing practice [7].

\section{B. Category 2: The Role of Feedback}

The second category is named the role of feedback. The researcher highlights students' performances base on the rubric and students' documents. Everything was written in minutes. This technique helps to the researcher to control what is the students' achievement, their weakness and strengths. In addition, this information allows the researcher to identify how to create strategies to improve her students' pre- writings because they must be lead to write by having a communicate purpose, which might make sense to them. Otherwise, it does not have sense if their writing topics might selected to the researcher because it is essential to profit students' interests, likes, needs or styles to have them write "if we are working on solving communicative problems, well-structured activities must be planned to have learners actively involved in the unveiling of any given concern by providing them with strategies and models as a way to solve a communicative problem like writing" [8].

With regard to this category, students in the pre-writing stage should accept their own mistakes, self-reflect on them increase their awareness about the use of English Language, and research skills. Unfortunately, this was a laborious work because many of them refused to accept their misconceptions about the language and the research process. That means, the writing academic process could not be completed if students do not give thoughtful consideration to their own learning and experience because they should be able to assess and understand their strengths and limitations in order to support their learning and academic development, but no only students are part of this process because professors should offer feedback timely and meaningfully. The feedback is like a constructive criticism "Good feedback should be part of a classroom assessment environment in which students see constructive criticism as a good thing and understand that learning cannot occur without practice" [9].

\section{Category 3: Theory for Academic Proposes}

This category focuses students looking for theory about their topics through efficient reading. There are two criterion of efficiency reading [10]: the first one is reading for pleasure and the second is reading to learn. This research was about reading to learn the center of attention because the first thing for students to do was to decide exactly what they wanted to get out of their readings according their topics selected previously, it helps to saves time in the end.

In this case, the researcher explained where and how can use resources. For instance, students relied on bibliographies from library catalogues in Meyer Library at Missouri State University, Universidad La Gran Colombia's Library and some data based that are online. Besides, the focus group helps to motivate students to read with visual aids and key questions given by the researcher, and encouraging active student's participation during the discussion was also an important role implemented in their research practices. Also, students reported problems with their reading comprehension 
on the focus group [11] "reading comprehension depends heavily on knowledge of language and print" [12]. Consequently, this category has some subcategories that show part of the organization of efficient reading [13].

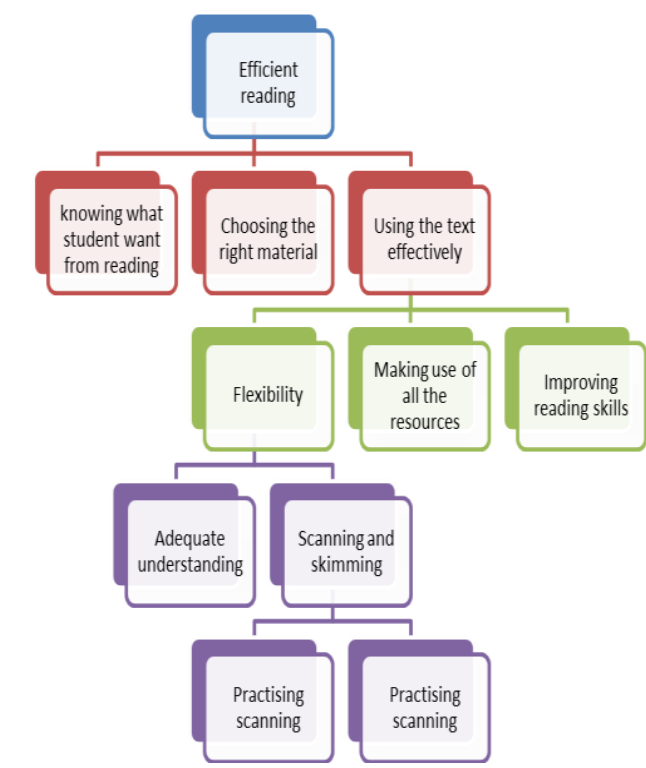

Fig. 1. Diagram showing the organization of effective reading.

\section{Category 4: Handling Language Rules}

The name of this category is based on grammar issues, spelling, word order, linking words, connector in a paragraph and its structure, and the most important how to use writing rules according to the manual of the American Psychological Association (APA) style. As a consequence, there were 14 (fourteen) feedbacks approximately (9 from the professor and 4 feedbacks from the two peer international evaluators and one feedback from a peer national evaluator, even though the exhausting revision for students' writing, they made many mistakes because some of them thought that writing in English language is the same that Spanish and others thought that English language grammar rules were odd or without sense. Although they know some rules, they do not understand why they permanently make the same mistakes once again.

Hence, every focus section and feedback had served as an expression for students and the researcher to improve and empower their writing. This category comes out from the analysis of the data. However, students now comprehend a little more about grammar issues, spelling, word order, linking words, connector in a paragraph and its structure, and the use of writing rules according to APA style. In fact, professor's email demonstrated student's worries and their enduring understandings about how rules are important in writing for building up meaning about the real issues that surrounds them in research process.

\section{CONCLUSION}

There are several points to value from data analysis: research training should not be understood as the transmission of knowledge already, but as the process that generates a set of guided experiences and guidance in which the student discovers and develops to contributes knowledge and skills own research work, makes use of them thoroughly and targeted, select the relevant skills to every situation and streamlines its work.

Furthermore, access to knowledge is necessary, but not sufficient. Learning to investigate involves learning a process, not content, thus, teaching strategies must be different, and it is vital that teachers, particularly if they are research methodology, have participated in research processes. For that reason, professor at the university should take into account the following recommendations:

1) Identify what is a research project.

2) Differentiate between research reports, review reports or documentation collection.

3) Distinction between different types of research.

4) Get adequate information is needed by databases.

5) Organize the research project completely.

6) Read research reports critically.

7) Prepare research reports written form.

8) Linking theory with the research process.

9) Delimitation of the topic and the research problem.

Motivation is a big point in the research writing process, for instance, their mood, feelings, self-confident and so on. All of them help to start the writing stage (pre-writing) using at the same time apps such as Facebook or twitter and extrinsic motivation where people or society recognized them as an important individual in their lives.

In fact, a "flexible curriculum", not only renewed the contents and methods, but also it help to implement the "credit" academic system for their management and organization. Now, academic staff has looked on curriculum and started talking about the resizing curricular perspective about skills that demand knowledge society and higher education like a cultural and social construction of academic members who interact in different learning environments, giving meaning to the education and assisting students' life.

From the references above Universidad La Gran Colombia establishes links between education, society and knowledge which allow consolidating the identity of institutions, academic and professional programs that form; considering that knowledge has no boundaries but occurs and is generated for a global society.

Transdisciplinary that transcends the discipline level to be located in the concrete reality to solve the social, culturalecological and scientist problems. At the same time, higher stage of reciprocity between disciplines. It is located beyond a specific science and can generate greater social or impact, ecological science, to transcend the limits of specialization or field of science to consolidate a space for the application of knowledge transforming the existing reality.

It is assumed to mediation the assessment of learning as it is a process of continuous and comprehensive evaluation of the human development of the students from the observation and analysis of the activities, interactions with science, with reality, with himself, with others and with the environment. This is done through fraternal support, to some caution to allow the student to act in an environment of trust, to consolidate systematizing their products in undergraduate work.

On the other hand, research and outreach for social impact interactions occur in an academic space that is conceived 
syncretism. Dependent on the training and scientific purpose, offers different scenarios both practical and theoretical, open, closed, individual and collective, large and small. Education at Universidad La Gran Colombia become learning scenarios, enter them requires respect, attitude and disposition to openness to others, the world and science.

Definitely, inquiry process allowed students to write more careful and accurate because it contributes to know new terms about the education and the relation with any specific topic and their own society, as well as finding some tools that define how to teach people with visual or auditory functional diversity. Besides, the main contributions of this kind of research articles are the students' lives and their experiences about the process of social and academic inclusion. Fortunately, good memories linked to the friendships made in a foreign country they are vital in the future and serve as contact unifying the language that in this case is English language.

\section{ACKNOWLEDGMENT}

Thanks to the staff at Universidad La Gran Colombia for the financial support and their academic training every day.

\section{REFERENCES}

[1] M. Foucault, Estrategias de Poder, Barcelona: Ediciones Paidós Ibérica, 1999.

[2] J. Nielsen and N. Arias, Análisis Crítico Sobre Los Referentes Teóricos de Stenhouse y Harris, Bogotá: inÉdito, 2012.

[3] L. Stenhouse, Investigación y Desarrollo Del Curriculum, Madrid: Ediciones Morata, 1984.

[4] M. Harris, Teorías de la Cultura en la Era Postmoderna, Barcelona: Critica S. L, 2007.

[5] J. Corbin and A. Strauss, Basic of Qualitative Research: Grounded Theory Procedures and Techniques, London: Sage, 1999.

[6] K. Hyland, Second Language Writing, Cambridge: Cambridge University Press, 2003

[7] D. Bryne, Teaching Writing Skills, USA: Longman, 1991.
[8] J. Harmer, The Practice of English Language Teaching, London, UK: Longman, 1991.

[9] S. Brookhart, How to Give Effective Feedback to Your Students, Alexandria: Associating for Supervision \& Curriculum Development, 2008.

[10] J. Palmer, "Focus group applications in higher education: Selected ERIC references," Journal of Applied Research in the Community College, pp. 75-89, 1994.

[11] J. Cummins, Supporting ESL Students in Learning the Language of Science, USA: Pearson, 2009.

[12] J. O'Malley and L. Valdez, Authentic Assessment for English Language Learners: Practical Approaches for Teachers, New York: Addison-Wesley Publishing Company, 1996.

[13] C. Nuttall, Teaching Reading Skills in a Foreign Language, Oxford: Heinemann English Language Teaching, 1996.

[14] M. Debus, Handbook for Excellence in Focus Group Research, Washintong D.C.: Academy for Educational Development, 1990.

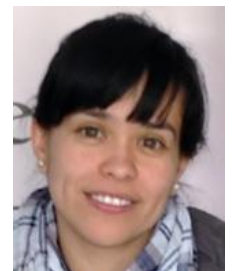

Jaddy Brigitte Nielsen Niño was born in Bogotá, Colombia. She hold a B.A in English, Spanish and French languages (2011), a diploma in TESOL and Spanish as a foreign language (2013), and the master educational degree in teaching (2013) and she is a graduate student ( $\mathrm{PhD}$ in educational research) at Universidad Internacional Iberoamericana de Mexico and graduated visitor student at Universidad Nacional de Colombia 2015-2016.

She has been professor at Universidad Nacional de Colombia and nowadays she is professor and researcher at Universidad La Gran Colombia, but at the same time, she is in charge of the internationalization process at School of Education at the same university. She has written some articles about her field "Education and research" those have been written in English and Spanish such as inclusion in the Superior Education: A Glance from the Process of the Functional Diversity, Texas, the United States of America: Global Education Journal, 2014, Adaptación y evaluación del Plan Casero como recurso educativo para estudiantes con necesidades especiales, Madrid, Spain: TEXTOS. Revista de Aprendizaje y Cibersociedad, 2015 and Developing Pluriculturalism and Inclusion for Global Citizens, Bogotá, Colombia: Universidad La Gran Colombia, 2015.

Prof. Nielsen has membership in professional societies called ASOCOPI and European Association of International Education. Finally, she has given lectures in Latin-American, the United States of America and Europe and she has received some awards like "Graduate Scholar Award" in Oregon, USA (2014) and Split, Croatia (2015). 